\title{
O NOVO CÓDIGO DE PROCESSO CIVIL E A POSSIBILIDADE DE OS TRIBUNAIS ADMINISTRATIVOS ANALISAREM A CONSTITUCIONALIDADE DE NORMAS
}

\author{
Pedro Guilherme Accorsi Lunardelli \\ Vanessa Damasceno Rosa Spina
}

\section{INTRODUÇÃO}

Com a edição do Novo Código de Processo Civil (NCPC), muitas questões anteriormente debatidas voltaram ao cenário jurídico, algumas delas com mais potência. A técnica processual de aplicação de precedentes que se tornou mais abrangente, a internalização no diploma processual de princípios constitucionais, a potencialização do princípio do contraditório e a introdução de medidas de cooperação entre as partes são exemplos de questões que foram, na sua grande maioria, profundamente modificadas, em evidente evolução processual.

Dentre todas as mudanças, uma delas nos salta aos olhos diante do seu alcance. Referimo-nos ao disposto no art. 15 do NCPC:

Art. 15. Na ausência de normas que regulem processos eleitorais, trabalhistas ou administrativos, as disposições deste Código lhes serão aplicadas supletiva e subsidiariamente.

A norma inserta no mencionado dispositivo trata, de forma expressa, sobre a aplicação dos comandos do Código de Processo Civil (CPC) aos processos trabalhistas, eleitorais e administrativos quando as normas regentes desses temas forem omissas ou incompletas.

Interessa-nos neste artigo, e é este ponto que abordaremos, a aplicação das normas processuais aos processos administrativos. Dentro desta análise, passaremos 
pela natureza das normas que regem os processos administrativos (ou seriam procedimentos administrativos?), pela função dos órgãos de julgamento e pelas competências - legais e constitucionais - para julgamento de constitucionalidade para, então, apresentarmos nossas conclusões sobre como as novas regras processuais afetam este cenário.

\section{A FORMA DE APLICAÇÃO DO NCPC AOS PROCESSOS ADMINISTRATIVOS: OMISSÃO OU INCOMPLETUDE DA NORMA}

Inicialmente, é importante tratarmos da distinção feita pelo mencionado art. 15 entre a aplicação da norma processual de forma supletiva e subsidiária. Cremos que ambas as expressões não são sinônimas, sendo uma aplicada quando a norma é omissa sobre determinado assunto e outra quando esta se revela incompleta.

Sobre essa distinção, rico é o magistério dos professores Paulo Cesar Conrado e Rodrigo Dalla Pria, ${ }^{1}$ para quem:

Na primeira situação, a da supletividade, o que se supõe é a total ausência de especial norma reguladora do processo administrativo, caso em que o Código de Processo Civil acaba por assumir função "normativo-substitutiva".

$\mathrm{Na}$ segunda hipótese, quando o assunto é a subsidiariedade, pressupõe-se alguma regulamentação, ostentando o Código de Processo Civil de 2015 função "normativo-complementar".

Feitas essas considerações iniciais, passemos à análise do efetivo reflexo dessa previsão contida na norma processual aos processos administrativos.

\section{A NATUREZA JURÍDICA DAS NORMAS QUE REGEM OS "PROCESSOS” ADMINISTRATIVOS E A ATIVIDADE JURISDICIONAL}

A primeira reflexão que se mostra relevante diz respeito à natureza das normas que regem os processos administrativos. Isso é de relevância irrefutável na

1 CONRADO, Paulo César; PRIA, Rodrigo Dalla. Aplicação do Código de Processo Civil ao processo administrativo tributário. In: CONRADO, Paulo César; ARAÚJO, Juliana Furtado Costa (Coord.). O Novo CPC e seu impacto no Direito Tributário. São Paulo: Fiscosoft, 2105. p. 251. 
medida em que a análise da natureza jurídica dessas normas pode nos levar ao entendimento de que são elas inconstitucionais, pois não seguem o regramento constitucional atinente à matéria.

Com efeito, dispõe o art. 22 da Constituição Federal que é competência da União federal legislar sobre processo:

Art. 22. Compete privativamente à União legislar sobre:

I - direito civil, comercial, penal, processual, eleitoral, agrário, marítimo, aeronáutico, espacial e do trabalho; [...].

E no art. 24 do Diploma Constitucional há a previsão para União, estados e Distrito Federal legislarem, de forma concorrente, sobre procedimento:

Art. 24. Compete à União, aos Estados e ao Distrito Federal legislar concorrentemente sobre:

I - direito tributário, financeiro, penitenciário, econômico e urbanístico; [...]

$\mathrm{XI}$ - procedimentos em matéria processual; [...].

Temos como premissa que os processos administrativos são efetivamente processo e não procedimento, diante das características das normas que o regulam.

Como bem pontuado por Vicente Greco Filho, " "do processo distingue-se o procedimento, que é a forma pela qual se sucedem os atos processuais. $O$ processo é algo mais profundo, uma verdadeira relação entre os sujeitos, e que foi explicado, em diversos momentos históricos, de forma diferente".

Prossegue esse mesmo autor ${ }^{3}$ apresentando as características atinentes às normas que regulam processo:

No processo, aos sujeitos que dele participam são atribuídos poderes, faculdades, deveres, sujeição e ônus, numa forma dinâmica, isto é, num suceder de atos que tendem para o ato-fim, a sentença, na qual aplica o direito.

O conjunto de normas e princípios que regula toda essa atividade é o direito processual. Este é autônomo em relação ao direito material que tem por fim realizar, mas é instrumental porque existe para essa finalidade.

2 FILHO, Vicente Greco. Direito Processual Civil brasileiro. 18. ed. São Paulo: Saraiva, 2005. p. 35.

3 FILHO, Vicente Greco. Direito Processual Civil brasileiro. 18. ed. São Paulo: Saraiva, 2005. p. 36. 
Assim, devemos ter em mente que tais normas regulam processo, na medida em que ele é o instrumento por meio do qual se exerce a jurisdição. E veremos mais adiante que a atividade exercida pelos julgadores é efetivamente atividade jurisdicional.

Adotando-se o raciocínio de que o processo administrativo é efetivamente modalidade de processo, temos de concluir que a norma que o disciplina deve ter seu regramento geral previsto em norma de âmbito nacional, pois assim disciplina o mencionado art. 22 da Constituição Federal. Mas sabemos que inexiste norma dessa estirpe regulando o processo administrativo. Tanto é verdade que tramita na Câmara dos Deputados o Projeto de Lei Complementar (PLP) n. 381/2014 (originário do Projeto de Lei do Senado n. 222/2013), que tem por finalidade criar normas gerais sobre o processo administrativo fiscal nos âmbitos federal, estadual, municipal e do Distrito Federal.

Tais ideias nos levam inevitavelmente ao pensamento de que as normas atualmente existentes são inconstitucionais. Não adentraremos este ponto, todavia, tendo em vista se tratar de aspecto a ser abordado de forma apartada e em momento mais oportuno com a devida profundidade que o assunto requer. Tomaremos, então, como pressuposto que as normas atualmente existentes e que regem os processos administrativos de forma geral são normas válidas.

Mas um ponto não abandonaremos: tais normas regem relações processuais. E contida nesse pensamento está a certeza de que a atividade exercida pelos órgãos de julgamento administrativos é efetiva atividade jurisdicional. Essa certeza advém da ideia de que jurisdição é uma função estatal que visa à justa composição de uma lide.

Das lições de Leonardo Greco ${ }^{5}$ podemos extrair a relação entre jurisdição, ação e processo: "a jurisdição é função, a ação é o direito de exigir do Estado o exercício da jurisdição; e o processo é o meio, o instrumento através do qual se exerce a jurisdição". Bem, se de processos estamos a tratar e o processo é o meio de se instrumentalizar a jurisdição, não há dúvidas de que a função exercida pelos julgadores administrativos é atividade jurisdicional.

4 "Ementa: Estabelece normas gerais sobre o processo administrativo fiscal no âmbito das administrações tributárias da União, dos Estados, do Distrito Federal e dos Municipios." Disponivel em: $<$ http://www.camara.gov.br/proposicoesWeb/fichadetramitacao?idProposicao=611441>. Acesso em: 18 out. 2018.

5 GRECO, Leonardo. Instituições de Processo Civil. 5. ed. Rio de Janeiro: Forense, 2015. p. 69. v. 1. 
Esse ponto é compartilhado pelo pensamento dos professores Conrado e Pria, ${ }^{6}$ para quem:

Como o judicial, o processo administrativo pode e deve ser visto como instrumento de jurisdição, portanto.

É certo, por óbvio, que essa jurisdição - a processada no ambiente administrativo - não experimenta as mesmas características da "jurisdição judicial"; fossem sobrepostas em todos os seus aspectos, seria sem sentido a distinção. Não obstante isso, é de jurisdição, definitivamente, o que se tem num e noutro âmbito.

Por certo, ao tratarmos de processo administrativo tributário - cuja sistemática exige que os órgãos de julgamento sejam compostos por membros da administração pública -, haverá dúvidas sobre a atividade jurisdicional exercida por esses membros. Não há de se confundir, contudo, a atividade jurisdicional exercida pelos membros da administração pública com a atividade administrativa dos cargos que exercem. Suas funções são administrativas até o momento que investidos da função jurisdicional, com a aquisição de atribuições distintas e roupagem distinta. Nesse momento, a figura do funcionário de carreira dá lugar à figura do julgador, acometido de imparcialidade.

O professor Celso Antônio Bandeira de Mello, ${ }^{7}$ notável conhecedor de direito administrativo, aponta com muita clareza as atividades desempenhadas como um dos critérios das funções exercidas pelo Estado :

Os critérios até hoje apresentados para caracterizar as sobreditas funções do Estado, em última instância, podem ser reduzidos, fundamentalmente, a apenas dois:

A) um critério "orgânico" ou "subjetivo", que se propõe a identificar a função através de quem a produz e B) um critério "objetivo" que toma em conta a atividade, que vale dizer, um dado objeto (não um sujeito). Este segundo critério, de seu turno, subdivide-se em dois:

6 CONRADO, Paulo César; PRIA, Rodrigo Dalla. Aplicação do Código de Processo Civil ao processo administrativo tributário. In: CONRADO, Paulo César; ARAÚJO, Juliana Furtado Costa (Coord.). O Novo CPC e seu impacto no Direito Tributário. São Paulo: Fiscosoft, 2105. p. 250.

7 MELLO, Celso Antonio Bandeira de. Curso de Direito Administrativo. 19. ed. São Paulo: Malheiros, 2005. p. 28-29. 
a) um critério (objetivo) material ou substancial, que busca reconhecer a função a partir de elementos intrínsecos a ela, isto é, que se radiquem em sua própria natural tipologia. Os que defendem tal critério (objetivo) material usualmente afirmam que a atividade característica da função legislativa se tipifica pela expedição de atos gerais e abstratos; a função administrativa por ser "prática", ou a realização da utilidade pública, e a atividade jurisdicional por consistir na solução de controvérsias jurídicas

b) um critério (objetivo) formal, que se apega essencialmente em características de direito, portanto, em atributos especificamente deduzíveis do tratamento normativo que lhes corresponda independentemente da similitude material que estas ou aquelas atividades possam apresentar entre si. Por este critério, o próprio da função legislativa seria não apenas generalidade e abstração, pois sua especificidade adviria de possuir o predicado de inovar inicialmente na ordem jurídica, como fundamento tão só na Constituição; o próprio da função administrativa seria, conforme nos parece, a de se desenvolver mediante comandos "infralegais" e excepcionalmente "infraconstitucionais", expedidos na intimidade de uma estrutura hierárquica; o próprio da função jurisdicional seria resolver controvérsias com a força jurídica da definitividade.

Analisando exatamente esse aspecto, assim se manifestou Leonardo Greco: ${ }^{8}$

Logo, desde que os agentes públicos que resolvam litígios ou tutelem interesses particulares no âmbito desses órgãos especializados estejam dotados das mesmas garantias de imparcialidade e independência conferidas aos juízes, e desde que exerçam essas atividades no intuito de reconhecer as posições de vantagem a quem a lei as atribua e não de sobrepor sistematicamente o interesse do Estado aos dos administrados, eles estarão exercendo função tipicamente jurisdicional.

Essas afirmações partem do pressuposto de que a atividade jurisdicional pode ser exercida por pessoas não investidas do cargo de juiz de direito:?

A jurisdição é exercida por órgãos independentes e imparciais, o que não significa, necessariamente, que ela deva ser exercida por juízes. A Convenção

8 GRECO, Leonardo. Instituições de Processo Civil. 5. ed. Rio de Janeiro: Forense, 2015. p. 72-73. v. 1.

9 GRECO, Leonardo. Instituições de Processo Civil. 5. ed. Rio de Janeiro: Forense, 2015. p. 70. v. 1. 
Americana de Direitos Humanos alude à jurisdição como uma função exercida por um "tribunal imparcial" (art. 8.).

Não é demais ressaltar que os tribunais administrativos atualmente existentes, como o Conselho Administrativo de Recursos Fiscais (CARF), o Tribunal de Impostos e Taxas (TIT), dentre outros, são todos formados por órgãos paritários, isto é, com metade dos seus representantes originária da administração pública, e a outra metade, dos contribuintes (indicados por órgãos de classe), o que os torna imparciais. E é exatamente essa imparcialidade que permite a todos eles o exercício da função jurisdicional.

Não se pode pensar que cada um deles, imbuído da sua função de julgador, procurará solucionar a lide no interesse daquele que representa, pois teríamos aí desvio funcional. Além disso, esses tribunais representam meros tribunais de passagem, que de nada serviriam para solução de litígios. Dúvidas, portanto, não há de que a função desempenhada pelos componentes dos tribunais administrativos no âmbito tributário é função jurisdicional.

Todos esses fatos nos direcionam no sentido de compreender que os processos administrativos fiscais não regem meros procedimentos, apesar de parte das normas que os regulam disciplinarem matérias procedimentais (mas também o CPC regula matéria procedimental). Temos como pressuposto, portanto, que os processos administrativos são efetivos processos.

Firmada essa premissa, vejamos como o NCPC, norma regulamentadora de processo, pode reavivar a questão da possibilidade de os tribunais administrativos analisarem constitucionalidade de normas.

\section{A EFETIVA APLICABILIDADE DO NCPC AOS PROCESSOS ADMINISTRATIVOS}

Desde a vigência do CPC de 1973, alguns de seus dispositivos eram aplicados aos processos administrativos, em especial àquilo que as normas de processos administrativos não previram. Exemplo disso era a distribuição do ônus da prova, para cujo assunto, em muitas oportunidades, era invocada a aplicação do CPC: ${ }^{10}$

10 Assim continua sendo, com os tribunais administrativos invocando dispositivos do NCPC: "Ementa. Assunto: Imposto sobre Produtos Industrializados - IPI. Periodo de apuração: 01/01/2001 a 31/12/2002. CRÉDITO-PRÊMIO DE IPI. PROVA. EFETIVA EXPORTAÇÃO. DOCUMENTAÇÃO. RAZOABILIDADE. 
Ementa. Assunto: Normas Gerais de Direito Tributário. Ano-calendário: 2006, 2007. DIREITO TRIBUTÁRIO. RELAÇÃO FISCO-CONTRIBUINTE. ÔNUS DA PROVA. PECULIARIDADES. A comprovação do fato constitutivo, extintivo ou modificativo do direito é ônus de quem alega, tal como dispõe a Lei nº 5.869, de 11 de janeiro de 1973 - Código do Processo Civil. No entanto, a omissão do contribuinte na prestação das informações requeridas pelo Fiscalização Federal que permitam atestar a existência do direito alegado, faz sobre ele recair o ônus pela não comprovação do fato controvertido.

A interpretação do texto normativo impõe o reconhecimento de que o conceito legal de insumo, terminologia empregada nas Leis 10.833/03 e 10637/02, não alcança a totalidade dos gastos necessários à realização do negócio da empresa.

Decisão: Vistos, relatados e discutidos os presentes autos. Acordam os membros do Colegiado, por unanimidade de votos, em rejeitar as preliminares e, no mérito, negar provimento ao Recurso Voluntário. (Processo Administrativo n. 16327.721770/2011-16, publicação: 23 mar. 2016, Relator Ricardo Paulo Rosa)

Também na vigência do antigo CPC, tínhamos a aplicação de precedentes decididos em recursos com repercussão geral e na sistemática dos repetitivos, além das súmulas vinculantes. Os primeiros passos nesse sentido se deram pela intenção (embora isso se mostre uma necessidade) de uniformização de entendimentos, quer pelo judiciário, quer pela administração pública.

E, com base em previsão constitucional, passou a ser obrigatória a observância, também pela administração, desses precedentes. Referimo-nos à Emenda

Imprescindivel a efetiva comprovação, por meio de documentação hábil, das exportações que ensejariam direito ao crédito-prêmio de IPI. Tendo sido essa prova apresentada pelo contribuinte por meio de guias de exportação carimbadas pelo CACEX, contrato de câmbio das operações, faturas das operações comerciais, bills of landing, seus Livros Diários do periodo e, por fim, planilha analítica vinculando todos esses dados referentes a cada uma das exportações, ocorridas nos ano de 1980 a 1981, com base no artigo $373 \S \S 1^{\circ}$ e $2^{\circ}$ do Novo Código de Processo Civil (distribuição dinâmica do ônus da prova) e do artigo $2^{\circ}$ da Lei n. 9.784/99, há de se entender comprovada a exportação para fins de aproveitamento do crédito-prêmio de IPI. Recurso voluntário provido. Decisão: Vistos, relatados e discutidos os presentes autos. Acordam os membros do Colegiado, por maioria de votos, em dar provimento ao recurso" (Processo Administrativo n. 11080.000687/2007-31, publicação: 11 jul. 2016, Relatora Thais de Laurentiis Galkowicz). 
Constitucional n. 45/2004, que acrescentou na Constituição Federal o art. 103-A tratando das súmulas vinculantes e da sua observância pelos órgãos da administração. Estava iniciado ali o caminho irreversível de aplicação de normas processuais, do âmbito judicial, a normas processuais, de âmbito administrativo.

Com a entrada em vigor do NCPC, esse caminho restou ainda mais certeiro, com a previsão expressa de que as normas processuais devem ser aplicadas também aos processos administrativos, consoante o já citado art. 15. Surge, então, uma questão: se cabe ao judiciário, no exercício da função jurisdicional, declarar a inconstitucionalidade de uma norma, caberia aos tribunais administrativos essa mesma função?

Bem, se as normas que regem os processos administrativos regem processo e o processo é o instrumento por meio do qual se busca a solução de um litígio, não tem lugar a ideia de que determinadas situações fiquem fora do alcance da atividade jurisdicional. Um órgão jurisdicional tem o dever de saneamento do processo, quer no âmbito judicial, quer no âmbito administrativo, bem como tem o dever de determinar a produção de provas de forma a viabilizar o direito à ampla defesa. Esses deveres são inerentes à atividade jurisdicional, como o é o dever de julgar o processo dentro dos limites em que ele se estabelece. Esta é a garantia assegurada pelo devido processo legal, cujo princípio constitucional deve ser observado em qualquer processo em qualquer esfera.

Não por outra razão o posicionamento do Supremo Tribunal Federal (STF) é claro em determinar a observância do due process of law por todos os órgãos de julgamento:

Cabe advertir, por necessário, considerada a essencialidade da garantia constitucional da plenitude de defesa e do contraditório, que a Constituição da República estabelece, em seu art. $5^{\circ}$, incisos LIV e LV, que ninguém pode ser privado de sua liberdade, de seus bens ou de seus direitos sem o devido processo legal, notadamente naqueles casos em que se viabilize a possibilidade de imposição, a determinada pessoa ou entidade, de medidas consubstanciadoras de limitação de direitos.

Impende assinalar, bem por isso, na linha de decisões que já proferi nesta Corte (RTJ 183/371-372, Rel. Min. CELSO DE MELLO - AI 306.626/ MT, Rel. Min. CELSO DE MELLO, v.g.), que o Estado, em tema de restrição à esfera jurídica de qualquer pessoa (inclusive das pessoas estatais), não pode exercer a sua autoridade de maneira abusiva ou arbitrária, desconsiderando, no exercício de sua atividade, o postulado da plenitude de defesa, pois 
o reconhecimento da legitimidade ético-jurídica de qualquer medida imposta pelo Poder Público de que resultem, como no caso, consequências gravosas no plano dos direitos e garantias individuais exige a fiel observância do princípio do devido processo legal (CF, art. 5\%, LIV e LV), consoante adverte autorizado magistério doutrinário (MANOEL GONÇALVES FERREIRA FILHO, "Comentários à Constituição Brasileira de 1988", vol. 1/65-66, 1997, 2a ed., Saraiva; PINTO FERREIRA, "Comentários à Constituição Brasileira”, vol. 1/176 e 180, 1989, Saraiva; JESSÉ TORRES PEREIRA JÚNIOR, “O Direito à Defesa na Constituição de 1988”, p. 71/73, item n. 17, 1991, Renovar; EDGARD SILVEIRA BUENO FILHO, "O Direito à Defesa na Constituição", p. 47/49, 1994, Saraiva; CELSO RIBEIRO BASTOS, "Comentários à Constituição do Brasil", vol. 2/280-285, 2004, 3a ed., Saraiva; MARIA SYLVIA ZANELLA DI PIETRO, "Direito Administrativo", p. 686/688, 25a ed., 2012, Atlas; LÚCIA VALLE FIGUEIREDO, "Curso de Direito Administrativo”, p. 443/456, 9a ed., 2008, Malheiros; HELY LOPES MEIRELLES, DÉLCIO BALESTERO ALEIXO e JOSÉ EMMANUEL BURLE FILHO, "Direito Administrativo Brasileiro", p. 108/109 e 767/768, 39a ed., 2013, Malheiros, v.g.). (Trecho do voto proferido pelo Min. Celso de Mello na Ação Cível Originária n. 2506 AgRg/DF)

Não é demasiado fazermos um paralelo dessa questão com o pronunciamento do STF no julgamento envolvendo o depósito prévio para os recursos administrativos em que o Ministro Joaquim Barbosa, tratando do direito de petição, reconheceu que a exigência representava uma violação a esse direito:

É comum, nos dias de hoje, a afirmação, de constitucionalistas americanos, de que o direito de petição contra órgãos do próprio executivo deve ser visualizado de acordo com as funções exercidas por este poder.

Com efeito, várias atividades do executivo se assemelham às atividades exercidas pelo Judiciário. Historicamente isso se explica. Antes da consagração, em diversos sistemas constitucionais, do sistema de separação de poderes, funções executivas e judiciais se confundiam. Ou seja, embora a Administração possua uma série de atividades em que o direito de petição não pode impedir sua margem de manobra, em outras, como nos procedimentos administrativos, o direito de petição se impõe como direito fundamental e inafastável. (Trecho do voto proferido pelo Min. Joaquim Barbosa no Recurso Extraordinário n. 389.383/SP, DJ: 29 jun. 2007) 
Esse mesmo direito de petição é assegurado nos processos administrativos tributários e o impedimento de análise de constitucionalidade da norma impugnada o fere de morte.

Dessa forma, se a discussão posta num determinado processo administrativo disser respeito à constitucionalidade de determinada norma, não pode o órgão de julgamento se furtar à sua análise. A negativa perpetrada pelos órgãos de julgamento administrativos representa uma negativa de prestação de tutela jurisdicional, em evidente desvio de finalidade e afronta ao devido processo legal.

Certo é, porém, que nem todas as competências das quais são imbuídos os juízes podem ser estendidas a qualquer outro órgão jurisdicional. Isso porque determinadas funções são constitucionalmente atribuídas a determinados tribunais, como a declaração de inconstitucionalidade de normas com efeito erga omnes. Essa competência está disciplinada pela Constituição Federal em seu art. 102, que assim dispõe:

Art. 102. Compete ao Supremo Tribunal Federal, precipuamente, a guarda da Constituição, cabendo-lhe:

I - processar e julgar, originariamente:

a) a ação direta de inconstitucionalidade de lei ou ato normativo federal ou estadual e a ação declaratória de constitucionalidade de lei ou ato normativo federal; [...].

Mas ponhamos atenção no fato de que este corte no exercício da jurisdição não é apenas para os órgãos de julgamento administrativos, mas também para os órgãos de julgamento judiciais. Quer-se dizer com isso que todos os órgãos que exerçam atividade jurisdicional podem sofrer limitações, e a declaração de inconstitucionalidade com efeito erga onmes é uma delas.

Isso não significa dizer que os órgãos de julgamento administrativos não podem analisar e proferir decisão com base em inconstitucionalidade de normas; muito pelo contrário, quer-se demonstrar que todos os órgãos de julgamento podem sofrer limitações sem que isso lhe retire a característica de um órgão jurisdicional.

Avançando ainda sobre essa questão, podemos verificar que os órgãos de julgamento administrativos, em determinadas oportunidades, acabam por analisar a constitucionalidade de normas, sem fazê-lo de forma aparente. Referimo-nos às situações em que os tribunais administrativos estaduais convalidam autos de infração lavrados com a finalidade de glosar créditos tributários decorrentes de benefícios fiscais concedidos por outros estados da federação, 
cuja norma não esteja amparada por autorização do Conselho Nacional de Política Fazendária (Confaz).

Tal conclusão é alcançada na medida em que, para que a lei concessiva do benefício fiscal fosse declarada inconstitucional, deveria o estado que se sentisse lesado ingressar com Ação Direta de Inconstitucionalidade (ADIn) para vê-la afastada e, com isso, não mais produzir efeitos. ${ }^{11}$ No entanto, o que os estados fazem é, verificando que a norma concessiva do benefício fiscal está em desacordo com a Constituição Federal e a Lei Complementar (LC) n. 24/75, lavrar autos de infração para glosar os créditos dos quais o contribuinte se apropriou com base naquela norma. E esses autos de infração são todos convalidados por decisões de órgãos de julgamento administrativos.

Pergunta-se então: esses órgãos não estão mantendo os autos de infração tomando como base a inconstitucionalidade de uma norma? Por certo que sim; mas não o fazem declarando a inconstitucionalidade de forma expressa. Admitimos, com isso, que os órgãos de julgamento administrativos (no caso citado, os estaduais), no exercício da sua jurisdição, já analisam a constitucionalidade de normas.

\section{CONSIDERAÇÕES FINAIS}

As disposições anteriores nos permitem concluir que as normas que regem os processos administrativos regulam efetivamente processo e não procedimento, cujos institutos são distinguidos pelas características que os cercam.

11 “I. TRIBUTÁRIO. LEI ESTADUAL QUE INSTITUI BENEFÍCIOS FISCAIS RELATIVOS AO ICMS. AUSÊNCIA DE CONVÊNIO INTERESTADUAL PRÉVIO. OFENSA AO ART. 155, § 2 $2^{\circ}$ XII, g, DA CF/88. II. CONTROLE DE CONSTITUCIONALIDADE. MODULAÇÃO DOS EFEITOS TEMPORAIS. 1. A instituição de beneficios fiscais relativos ao ICMS só pode ser realizada com base em convênio interestadual, na forma do art. $155, \S 2^{\circ}$, XII, g, da CF/88 e da Lei Complementar $n^{\circ}$ 24/75. 2. De acordo com a jurisprudência do STF, o mero diferimento do pagamento de débitos relativos ao ICMS, sem a concessão de qualquer redução do valor devido, não configura beneficio fiscal, de modo que pode ser estabelecido sem convênio prévio. 3. A modulação dos efeitos temporais da decisão que declara a inconstitucionalidade decorre da ponderação entre a disposição constitucional tida por violada e os princípios da boa-fé e da segurança juridica, uma vez que a norma vigorou por oito anos sem que fosse suspensa pelo STF. A supremacia da Constituição é um pressuposto do sistema de controle de constitucionalidade, sendo insuscetivel de ponderação por impossibilidade lógica. 4. Procedência parcial do pedido. Modulação para que a decisão produza efeitos a contatar da data da sessão de julgamento" (ADI n. 4481, Relator Min. Roberto Barroso, Tribunal Pleno, julgado em: 11 mar. 2015, processo eletrônico DJe092, divulgação: 18 maio 2015, publicação; 19 maio 2015). 
Em se tratando de processo, somos levados à inevitável ideia de que a atividade de julgamento exercida pelos órgãos administrativos é atividade jurisdicional (o processo é o instrumento para o exercício da jurisdição). Assim, se de processo e de jurisdição estamos falando, somos obrigados a concluir que os processos administrativos se subordinam ao princípio do devido processo legal e do direito de petição.

Inafastável, portanto, se mostra a possibilidade de os tribunais administrativos analisarem a constitucionalidade de normas, quando os órgãos de julgamento forem provocados para tanto. Se a função que os cabe é a de julgador, inevitável é o exercício da jurisdição dentro dos limites em que posta à apreciação. Ainda, como se viu, a análise de constitucionalidade já é exercida pelos tribunais administrativos, sem que se faça de modo expresso.

Mas se havia qualquer dúvida a respeito dessa competência dos órgãos de julgamento administrativos, estas foram extintas, ou no mínimo minimizadas, com a edição do NCPC, quando previu a aplicação das regras processuais judiciais também para os processos administrativos. E se normas regulamentadoras do processo administrativo preveem limitação aos tribunais administrativos de analisarem constitucionalidade de atos normativos, resta-nos concluir que essas normas não mais são compatíveis com o ordenamento jurídico. 
